\title{
دور المعلم في تنمية أنماط التفكير الناقد في حصص الرياضيات والعلوم في مراحل التعليم الأساسي في دولة الكويث
}

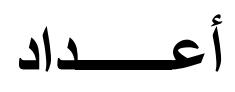

د. دلال فرحان العنزي د. ابتسام العقيل د. منال الديحانى كلية التربية الأساسية

مجلة الدراسات التربوية والانسانية ـ كلية التربية ـ جامعة دمنهور

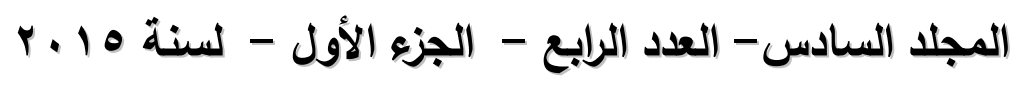


فاعلية استراتيجية التصور البصرى فى تنمية مهارات الإملاء والاتجاه نحو الكتابة د. صفوت توفيق هنداوى 


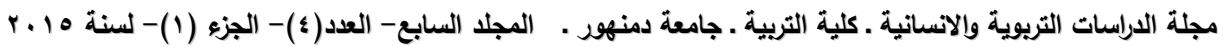


دور المعلم في تنمية أنماط التفكير الناقد في حصص الرياضيات والتلوم في

مراحل التعليم الأساسي في دولة الكويت

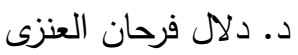

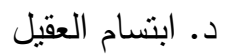

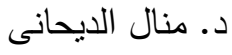

ملخص الاراسـة:

هدفت الدراسة إلى بيان الدور الذي يلعبه المعلم في تتمية أنماط التفكير الناقد،

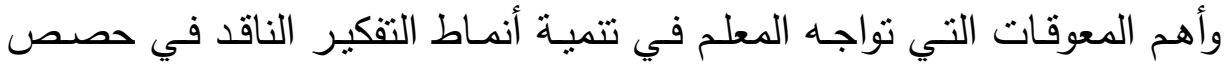

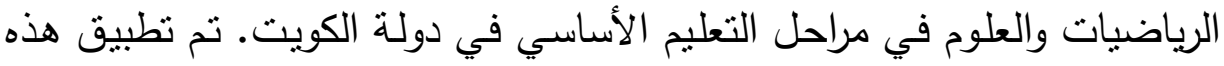

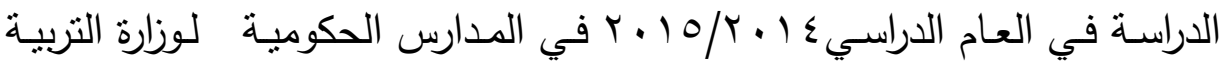

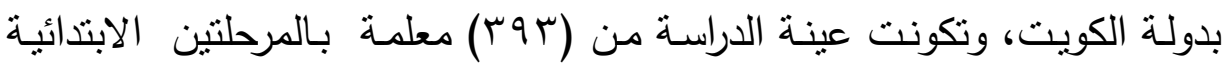
والمتوسط من عدة مناطق تعليمية في الكويت، يمتلون معلمات مادة الرياضيات

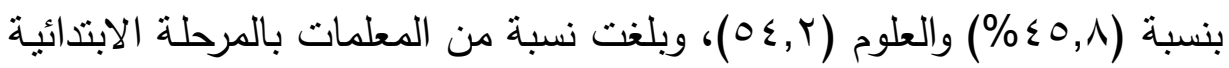

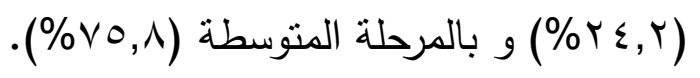

أنتارت النتائج الى أن المعلمات يستخدمن تتمية التقكير الناقد في التدريس للطلبة بمستوى مرتفع بمتوسط قيمته ( (r,r)، وقد قيمت المعلمات استخدامهن لأنماط

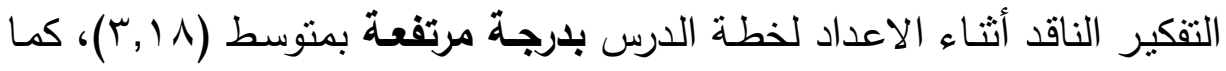
قدرن استخدامهن لأنماط التفكير الناقد أثناء عرض الدرس بدرجة مرتفعة بمتوسط بلاء

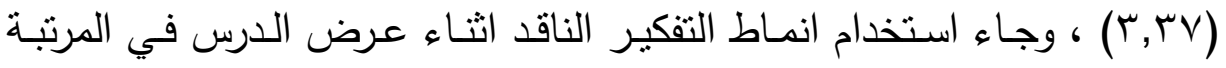

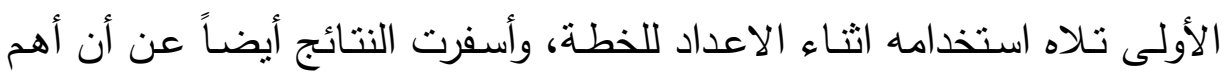
المعوقات التي تواجـه المعلم هي عدم وجود خطـة متقنـة لتتميـة انمـاط التفكير

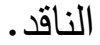




\section{المقدمـــــة}

في ظلـل التطـور العلمـي السـريع، بـدت الحاجـة الماسـة للرياضـيات والعلـوم

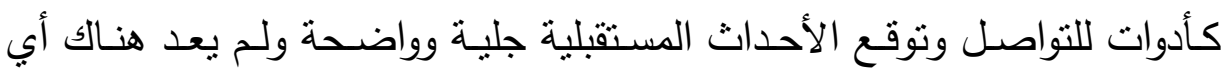

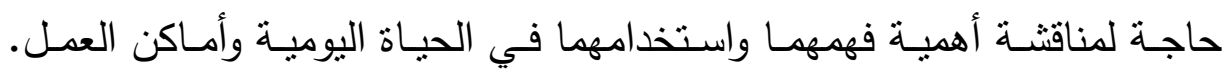

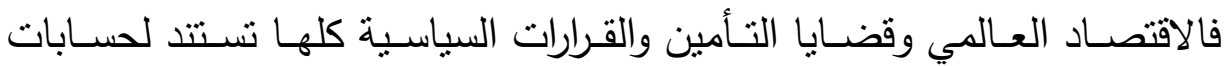

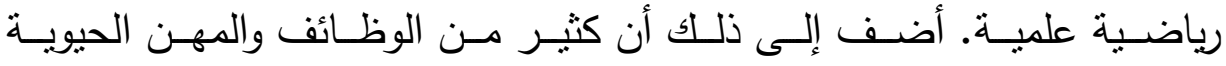

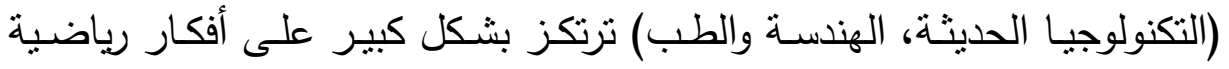

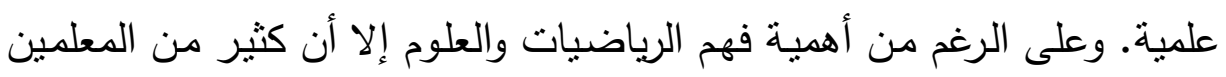

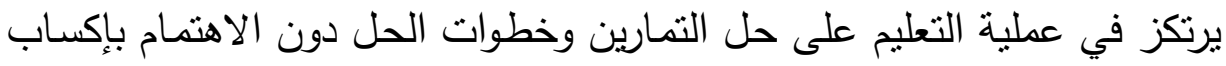

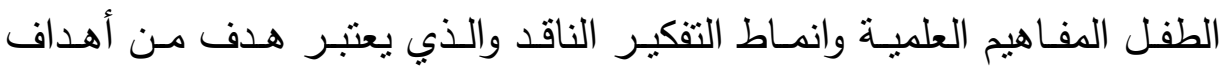

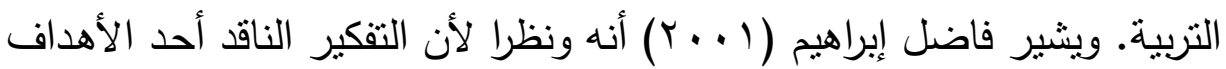
التي تسعى التربية إلى تتميته لدى الطلاب، لذا وجب توجيه التعليم لتتمية القدرات النقدية كمفهوم جديد للمعرفة والتعلم، لما له من أهمية في مواجهة إفرازات الثورة المعرفية التقنية الهائلة.

نظـرا لمـا للتفكير الناقد مـن أهميـة في التعليم وتطوير شخصيات الطـلاب واكسـابهم الاسـتقلالية في التفكير ، فقد أكدت الكثيـر مـن الدراسـات والأبحـاث والمؤتمرات العلمية على ضرورة تتمية التفكير بأنواعه المختلفة بما فيها التفكير

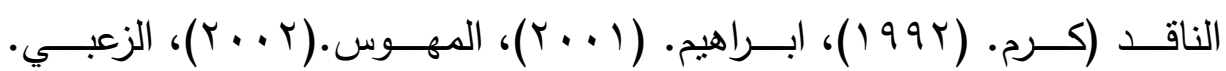

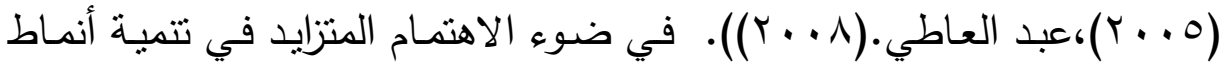
التفكير الناقد واستراتيجيات التفكير بشكل عام في حصص الرياضيات والعلوم،

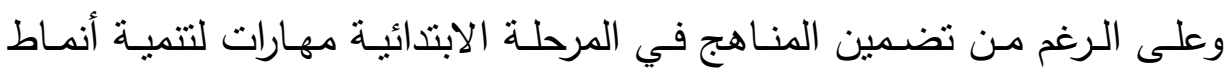
التفكير المختلفة إلا أنه: 
ا. يتم التركيز في الحصص على تعليم خطوات وإجراءات حل التمارين فقط لاجتياز الاختبار بغض النظر عن فهم واستيعاب الطالب للمفاهيم العلمية

والرياضية.

r.إهمال تتمية أنماط التفكير الناقد والتي تعتبر جوهر العملية التعليمية بشكل عام ولب تعليم الرياضيات والعلوم بشكل خاص. r.رهبة معلم الرياضيات والعلوم من تقديم أفكار وتمارين جديدة للأطفال خوفا لريال من فثلهم في التوصل للحل. 1-أهداف الدراسة:

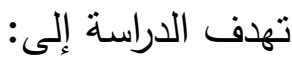
1 بيـان أهميـة اسـتخدام استراتيجيات التفكير الناقد في حصص الرياضـيات والعلوم في مراحل التعليم الأساسي. r.الكثَف عن الآليـة المتبعـة في تدريس مـادة الرياضيات والعلوم في مراحل التعليم الأساسي. r.تحديد استراتيجيات تتمية أنماط التفكير الناقد في حصص الرياضيات والعلوم.

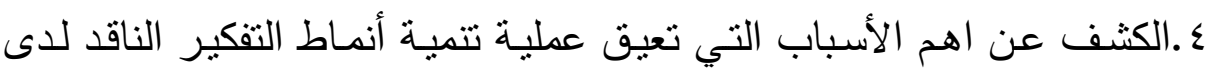

التناميذ.

\section{ب أهمبة الاراسة:}

تكتسب الدراسة أهميتها من خلال:

ا ـ بيـان أهميـة الارتقاء بالعمليـة التعليميـة وأسـاليب وطـرق التدريس مـن

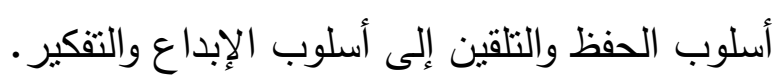

r. توضيح جوانب الضعف في تدريس مادتي الرياضيات والعلوم واعتمادها على خطوات وإجراءات حل التمارين، وأهم معوقات تتمية أنماط التفكير

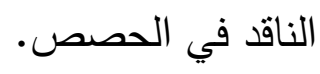
r. تقديم استراتيجيات لمعلم الرياضيات والعلوم لتتمية أنماط التفكير الناقد. 
مصطلحات الاراسية:

التفكير الناقد: فحص وتقيميم الحلول المعروضة \&oore, McCann, \& )

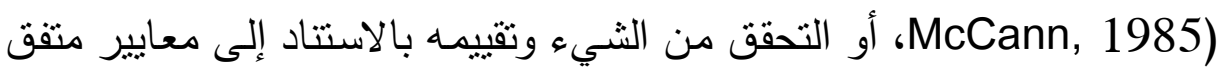
(Udall, Daniels, 1991). عليها مسبقاً مرحلة التعليم الأساسي: تتشتل مرحلة التعليم الأساسي على المرحلة الابتدائية

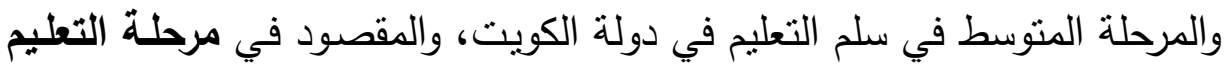

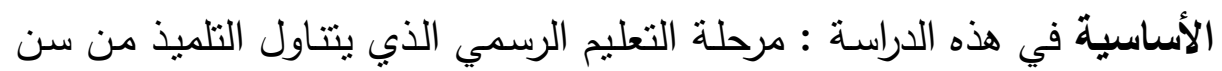
السادسة، إلى الخامس عشرة، فيتعهده بالرعاية الروحية، الجسمية، والفكرية،

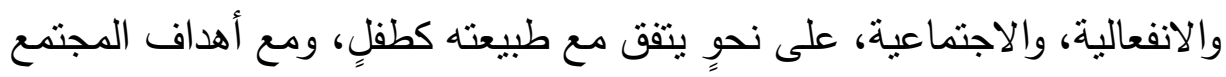
الّّي يعيش فيه، وهي مرحلتي التعليم الابتدائي والمتوسط. حدود البحث:

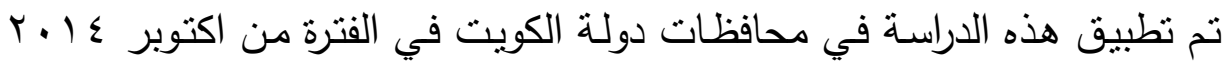

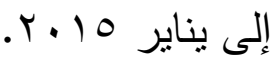

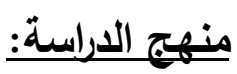
يستخدم الباحث المنهج الوصفي التحليلي للتعرف على استراتيجيات التفكير الناقد

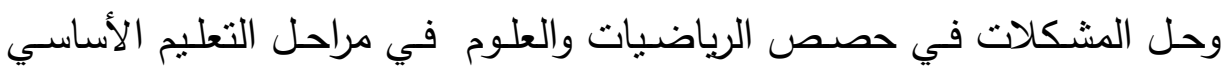
وتزويد الميدان بهذه الاستراتيجيات. الإطار النظري: أهمبة التفكيز الناقد

تدرج المعايير التربوية الحديثة مهارات التفكير الناقد كمنطلب أساسي لتعليم المواد المختلفة حيث أن تتمية القدرة على التفكير الناقد تمكن الفرد من اكتساب المعرفة

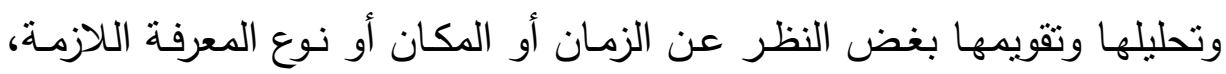
فالتفكير الناقد لم يعد خياراً بل ضرورة تربوية يفرضـها التطور العلمي السريع.

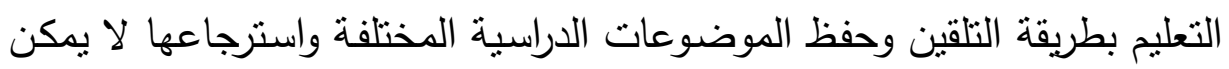


الطلبة من امتلالك طرق التفكير الناقد والمهارات العقلية المختلفة. ويعزي الحموي

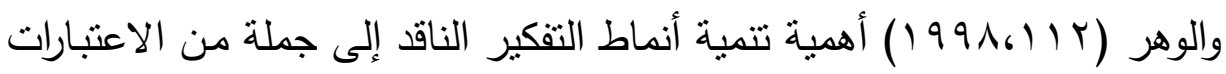

•تميـة أنماط التفكير الناقد لدى الطلاب يؤدي إلى فهم أعمق للمحتوى المعرفي الذي

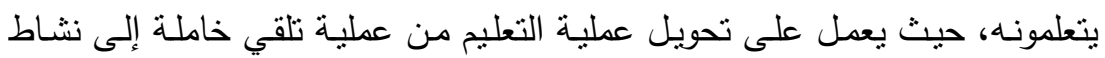

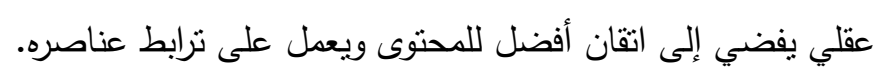

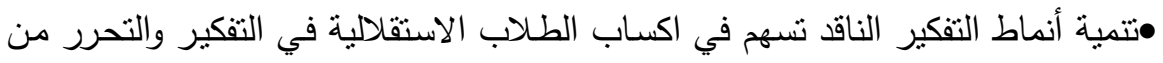

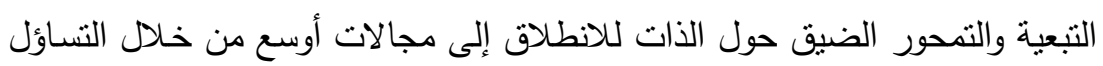
والبحث وعدم التسليم بالحقائق دون التثبت منها واستكثافها.

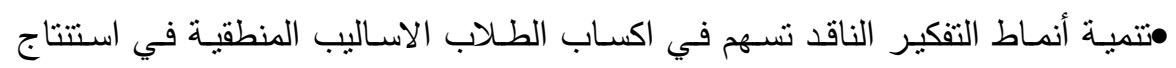
الأفكار وتقسيرها.

ويرى منسي (r . . r) أن أسلوب التفكير الناقد لا يحتاج فيه الفرد لحل مشكلة معينة بأسلوب علمي وابتكاري، إنما يتطلب منه دراسة الأفكار والآراء واختبارها ومن ثم استخلاص رأي أو حكم عليها، وهو يركز على الدقة في ملاحظة الوقائع المتعلقة بالموضوع وتقويمها واستخلاص النتائج منها بطريقة علمية سليمة.

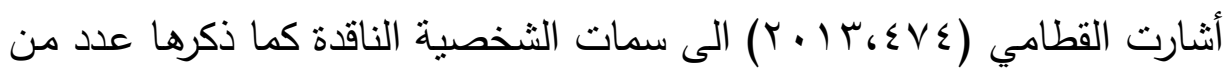

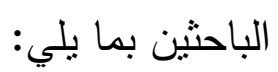

ا. بانفتح الذهن نحو الأفكار الجديدة.

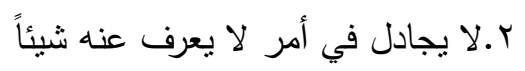
r.بحاول الفصل بين التفكير العاطفي والمنطقي. ع بيستكثف ويتخيل البدائل. ه.بحاول تجنب الأخطاء الثائعة في تحليل الأمور.

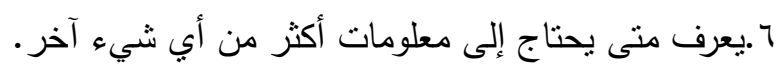

V.يعرف الفرق بين النتيجة الني قد تكون حقيقة والنتيجة التي يجب أن أن تكون حقيقة. ^.ينحرى الدقة في تعبيراته اللفظية وغير اللفظية. 
أجري نجم (11 (1) في المملكة الأردنية الهاشمية دراسة بعنوان "أثز استخدام أسلوب حل المشكلات في تدريس الرياضيات في تتمية التفكير الناقد لدى طلبة

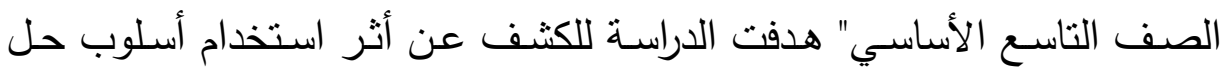
المشكلات في تتمية التفكير الناقد. وقد طبقت الدراسة على عينة من (19) طالبا

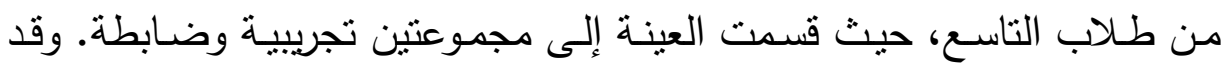

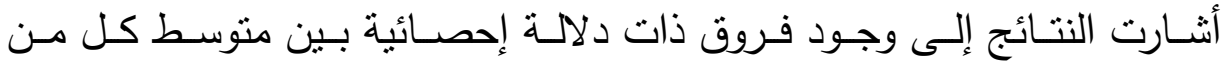

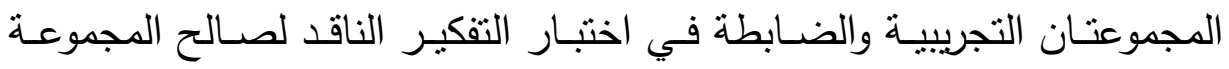
التجريبية.

وفي دراسة أجراها إليوت (Elliot,2000) هدفت للتعرف على أثر دراسة مقرر جامعي في الجبر في تتمية مهارات التفكير الناقد لدى الطلبة. وعلى الرغم من

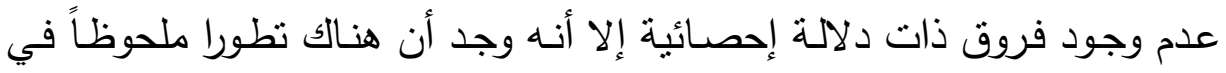

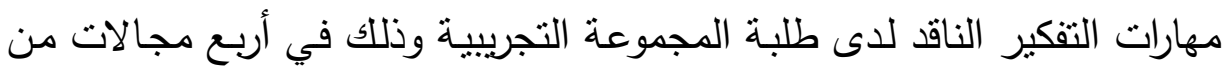
مجالات اختبار واطسن-جليسر الخمسة. وفي دراسـة قـام بها الخزام (991 (19) هدفت للبحث في أثر كل مـن طريقـة

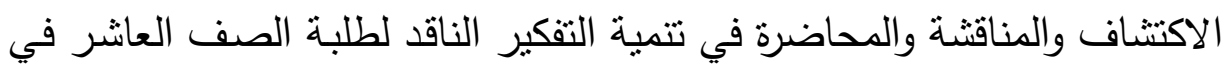

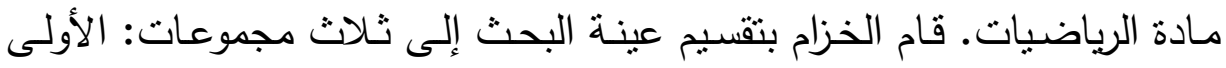
تدرس بطريقة المحاضـرة، والثانية بطريقة المناقثـة، والثالثة بطريقة الاكتثـاف،

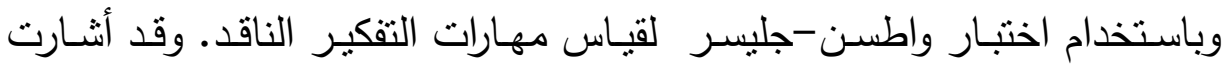
نتائج الدراسة إلى تفوق طريقة التدريس بالاكتشاف على كل من طريقتي المناقثنة

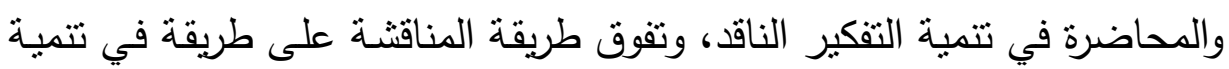
التقكير الناقد، وعدم وجود أثز لطريقة المحاضرة في تتمية التفكير الناقد. وفي دراسـة بعنوان " التقكير الناقد في عصر المعلوماتيـة" قام بها د. حسن

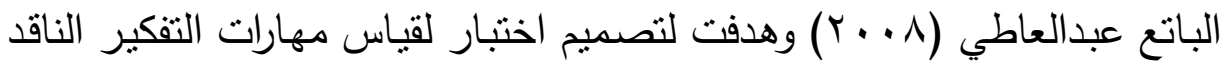
لاى طلاب الجامعة ومن ثم حساب ثباته وصدقه لتطبيقه في الميدان، وقد تم 
التوصل لخمس مهارات رئيسية للتفكير الناقد وهي: مهارة تحديد الفكرة الرئيسية التي يدور حولها الموضوع، ومهارة جمع المعلومات المتعلقة بموضوع ما، ومهارة تحديد التتاقض في المعلومات، ومهارة التحليل، ومهارة تقويم الحجج. وفي دراسـة قام بها فتح الله (9 . . ب) هدفت لدراسـة أثر استراتيجية خرائط التفكير القائمـة على الدمج في تتميـة التحصيل في مـادة العلوم والتفكير الناقد والاتجاه نحو العمل التعاوني لدى تلاميذ المرحلة المتوسطة في المملكة العربية

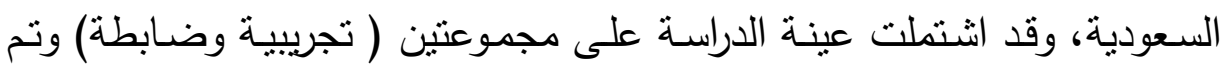
اختيار أفراد المجموعتين بشكل عشوائي من فصول مدارس التعليم العام بالمرحلة

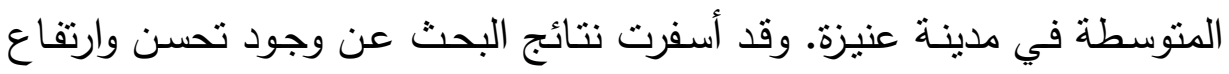
دال إحصـائيا في التفكير الناقد لتلاميذ المجموعـة التجريبيـة بمقارنتهم بتلاميذ المجموعة الضابطة، كما أوضحت النتائج أوضحت النتائج حجم تأثنير استخدام استراتيجية خرائط التفكير القائمة على الدمج في تتمية التفكير الناقد كبير . إجراعات الدراسة:

تعتمد هذه الدراسـة في جمع البيانات من الميدان ومن ثم معالجتها إحصائياً

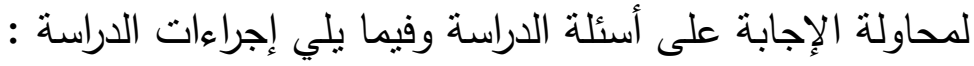

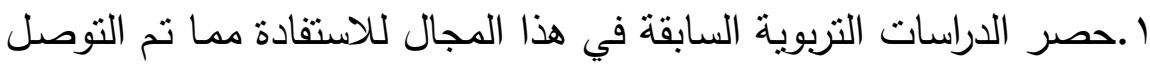
إليه العلم في تتمية أنماط التقكير الناقد. r.اعداد أداة قياس (استبانة) وتطبيقها على معلمي الرياضيات والعلوم. تكونت الاداة المستخدمة من استبيان لقياس دور المعلم في تنمية التفكير الناقد، وقد اشتمل المقياس على جزئيين، الجزء الأول يشمل المعلومات الأساسية عن الاستبيان، و تضم المنطقة التعليمية ، و المرحلة التعليمية

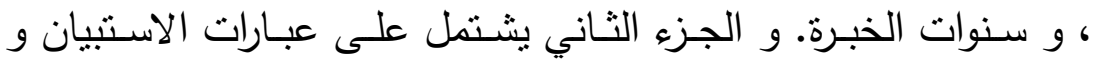

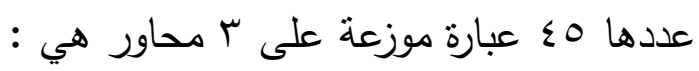


أ-محور دور المعلم في تتمية التفكير الناقد أثناء الاعداد لخطة الدرس

$$
\text { (1) (1) عبارات) }
$$

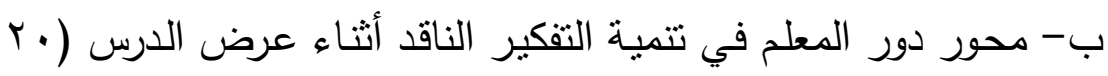

$$
\text { عبارة). }
$$

ت- محور معوقات نتمية التفكير الناقد في التدريس (V) عبارة). و تتم الاجابة على الاستيان على مدرج رباعي للاستجابة (دائما، عادة ، نادرا، لـانه

$$
\text { اطلاقا) تأخذ القيم من (ع، ب م ، ؟، ( ). }
$$

\section{عينة الدراسة:}

تكونت عينة الدراسة من بqج معلمة بالمرحلتين الابتدائية و المتوسط من عدة

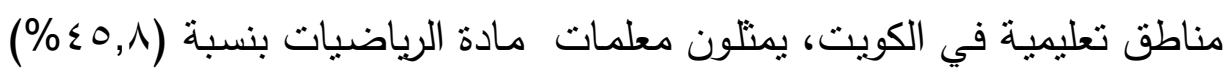

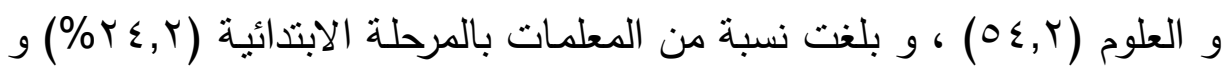

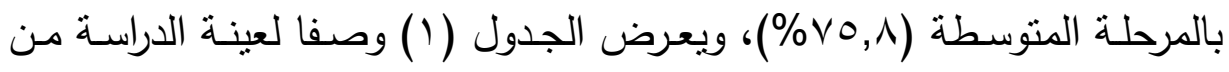

\begin{tabular}{|c|c|c|c|}
\hline$\%$ & العدد & الفئات & المتغير \\
\hline 15.5 & 61 & الأحمدي & \multirow{4}{*}{ المنطقة التعليمية } \\
\hline 20.6 & 81 & |لعاصمة & \\
\hline 18.6 & 73 & |الفروانية & \\
\hline 45.3 & 178 & الجهراء & \\
\hline 24.2 & 95 & ابتّائي & \multirow{2}{*}{ المرحلة التعليمية } \\
\hline 75.8 & 298 & متوسط & \\
\hline 30.3 & 119 & $1-5$ & \multirow{4}{*}{ سنوات الخبرة } \\
\hline 41.7 & 164 & 6- 10 & \\
\hline 15.0 & 59 & 11- 15 & \\
\hline 13.0 & 51 & اكثر من 10 & \\
\hline 100.0 & 393 & & موץ \\
\hline
\end{tabular}
حيث المنطقة التعليمية و المرحلة التعليمية، و الخبرة. جدول (1) جله اله عينة الاراسة 


\section{حساب صدق الاستيبان :}

تـم التحقق مـن صـدق الاسـتيان بحسـاب الاتســاق الـداخلي لمحـاوره، و ذلـك باستخدام معامل ارتباط بيرسون لحساب العلاقة الارتباطية بين درجة كل فقرة

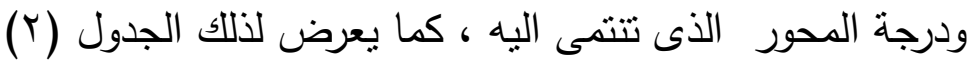

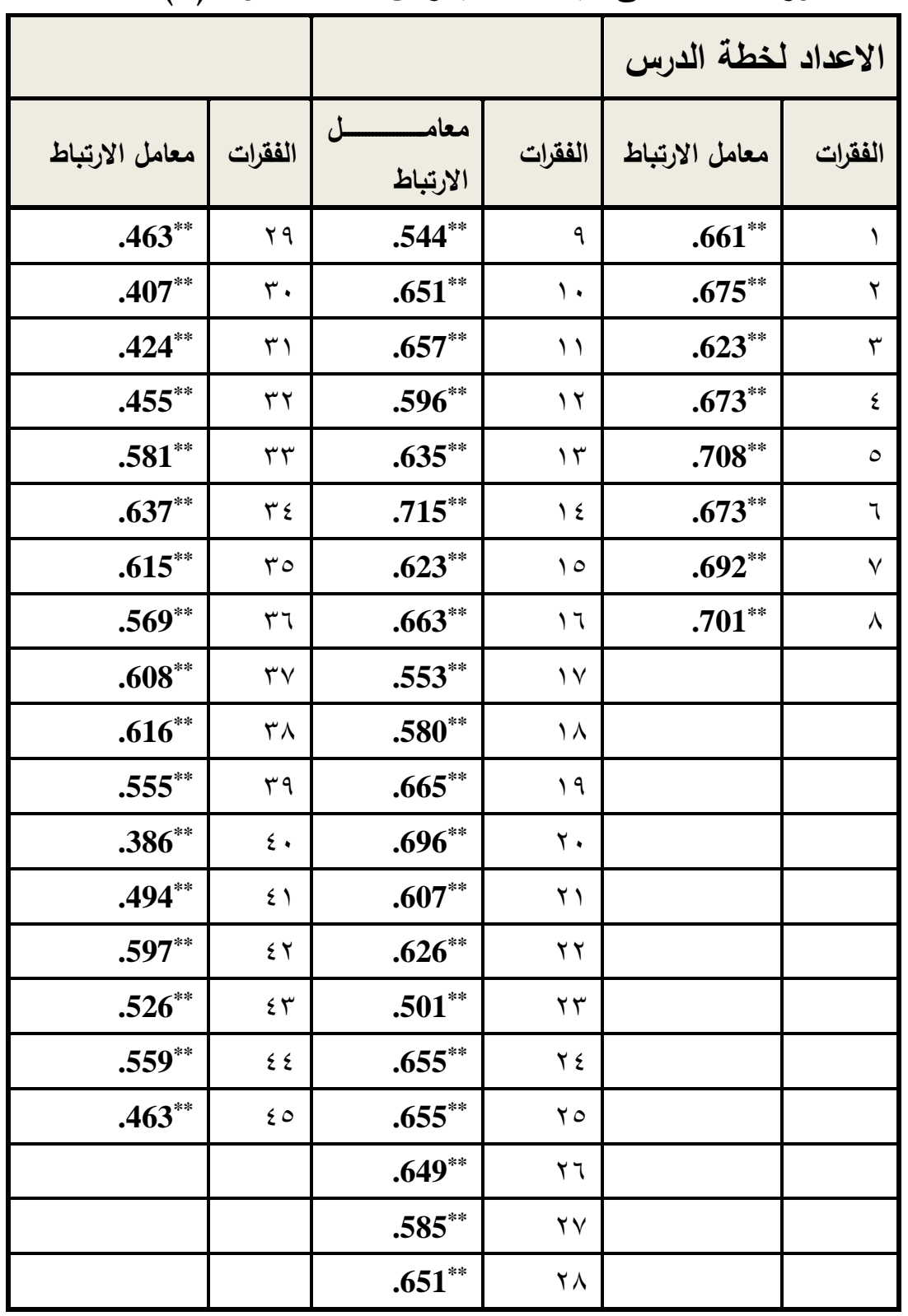


جدول (ץ): حساب الاتساق الاخلي لمحاور الاستبيان **دالة عند مستوى ل.,...

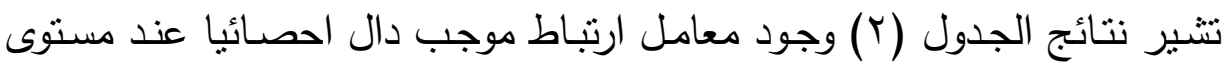
( ( . • ) بين جميع فقرات الاستبيان وبين أبعاده الفرعية وتراوحت قيم معاملات

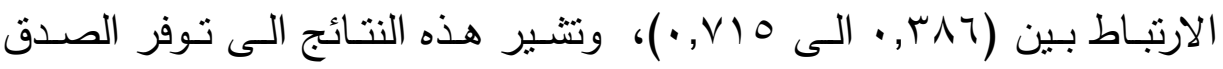
الداخلي بمحاور الاستبيان.

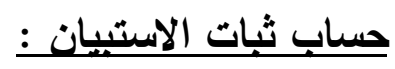

تم التحقـق مـن ثبـات الاسـتبيان باسـتخدام طريقتـي كرونبـاخ ألفـا، و التجزئسة

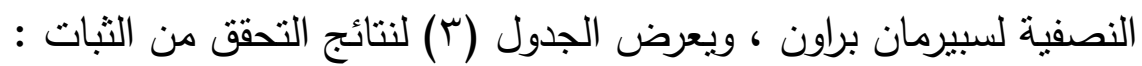

\begin{tabular}{|c|c|c|c|}
\hline | معامــلـيل التجزئـــة & كرونباخ لـــــل & عـالعبارات & المحاور \\
\hline .850 & .819 & 8 & الاعداد لخطة الارس \\
\hline .929 & .917 & 20 & عرض الارس \\
\hline .849 & .842 & 17 & المعوقات \\
\hline
\end{tabular}

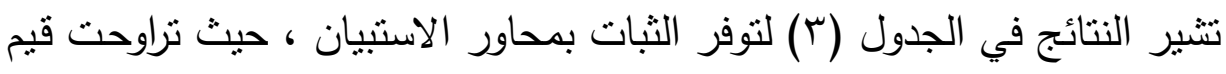

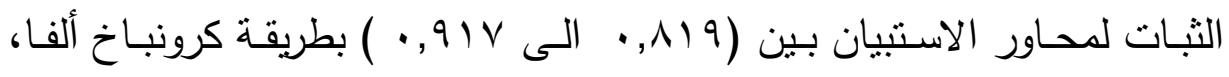

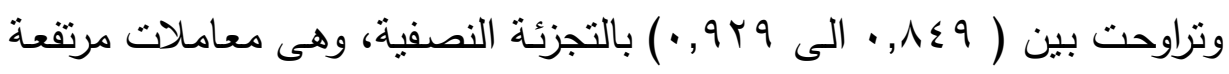
تنين توفر الثبات بمحاور الاستبيان بدرجة مرتفعة.

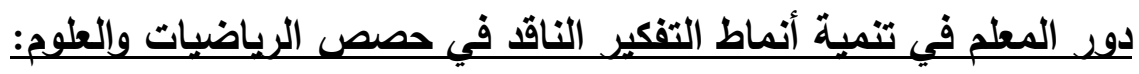

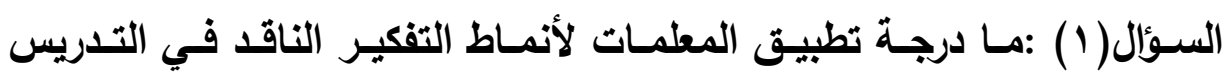

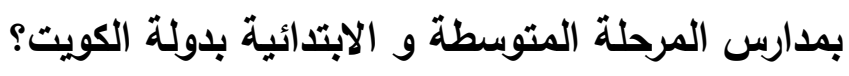

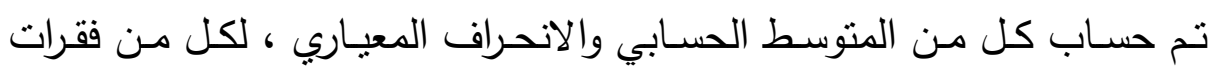
محوري الاعداد لخطـة الدرس وعرض الدرس، و تم اعتمـاد المستويات التاليـة للتعرف على مستوى التطبيق لأنماط التفكير الناقد : 
فاعلية استراتيجية التصور البصرى فى تنمية مهارات الإملاء والاتجاه نحو الكتابة د. صفوت توفيق هنداوى

\begin{tabular}{|c|c|c|c|c|}
\hline الترتيب & المستوى & 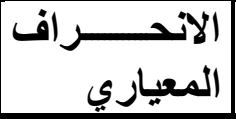 & الحستوسي & حاور - \\
\hline 2 & 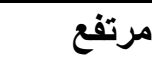 & .516 & 3.18 & أنثناء الاعداد لخطة الدرس \\
\hline 1 & مرتفع & .448 & 3.37 & أثناء عرض الارس \\
\hline & 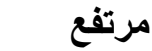 & .423 & 3.31 & سط مجموع المحاور \\
\hline
\end{tabular}

جدول (ع) : المتوسطات و الانحراقات المعيارية لاستخدام التفكير الناقد في التدريس'

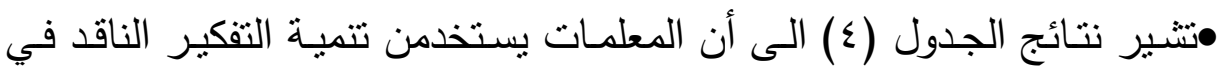
التدريس للطلبة بمستوى مرتفع بمتوسط قيمته (اب, (ب) . •وقد قيمت المعلمات استخدامهن لأنماط التفكير الناقد أنثاء الاعداد لخطة الدرس بهرس

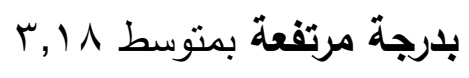

•كما قدرن استخدامهن لأنماط التفكير الناقد أثتاء عرض الدرسيط برس بدرجة مرتفعة

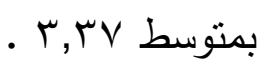

•وقد جاء استخدام انماط التفكير الناقد اثثاء عرض الدرس في المرتبـة الأولى لأل تلاه استخدامه اثناء الاعداد للخطة

\begin{tabular}{|c|c|c|c|c|}
\hline 高: & 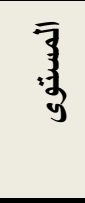 & $\overline{\bar{y}} \overline{3}$ & $\sqrt{3}$ & الفقرة \\
\hline 1 & مرتفع & .659 & 3.43 & 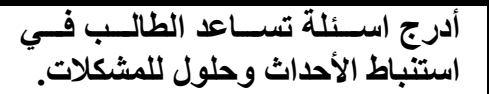 \\
\hline$r$ & مرتفع & .660 & 3.38 & 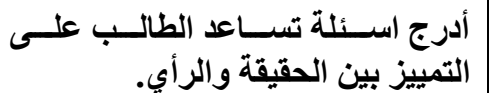 \\
\hline
\end{tabular}

ويعرض الجدول التالي لتقييم عينة الدراسة لبنود محور الاعداد لخطة الدرس:

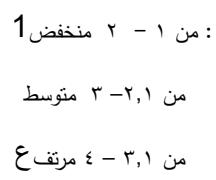




\begin{tabular}{|c|c|c|c|c|c|}
\hline$r$ & مرتفع & .735 & 3.34 & أديثث أسئلة تصفب الحدث الصلة بين حديثين & $r$ \\
\hline$\varepsilon$ & مرتفع & .697 & 3.34 & بحل المشكلة مسبقاً. ألطالب مـن التبـؤ & 1 \\
\hline 0 & مرتفع & .656 & 3.31 & 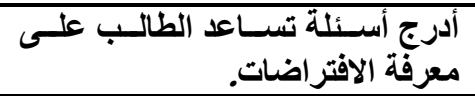 & $r$ \\
\hline 7 & مرتفع & .766 & 3.23 & 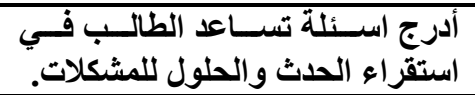 & V \\
\hline$v$ & مرتفع & .830 & 3.05 & 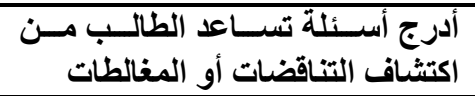 & 0 \\
\hline$\wedge$ & متوسط & 1.108 & 2.35 & 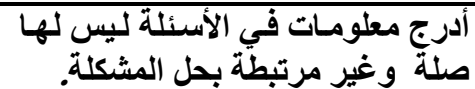 & $\varepsilon$ \\
\hline
\end{tabular}

جدول (0): المتوسـطات الحسـابية و الانحرافـات المعياريـة لبنـود محسور "الاعـداد لخطـة

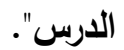

تبين نتائج الجدول (0) أن مستويات تقييم المعلمات لاستخدام التفكير الناقد في الاعداد لخطة الدرس قد تراوحت بين المتوسـط الـى المرتفع، و قد حصـلت غالبيـة البنـود على مسـتوى مرتفع (V) عبـارات، وحصـلت عبـارة واحدة على مسـتوى منخفض. وقد جاء في الترتيب الأول العبارة رقم (^) "أدرج اسئلة تساعد الطالب في استتباط الأحداث وحلول للمشكاثت" بمستوى مرتفع، و فى الترتيـب الأخير العبارة رقم (ع) "أدرج معلومات في الأسئلة لبس لها صلة وغبر مرتبطة بحل المشكلة" بمستوى متوسط. يعرض الجدول التالي لتقييم عينة الدراسة لبنود محور عرض الدرس :

\begin{tabular}{|c|c|c|c|c|c|}
\hline 浔 & 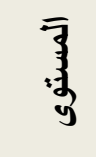 & $\begin{array}{ll}\overline{7} & \overline{3} \\
\overline{3} & \overline{3} \\
\overline{3}\end{array}$ & $\begin{array}{ll}\overline{3} & \overline{3} \\
3 & \end{array}$ & الفقرات & p \\
\hline 1 & مرتفع & .541 & 3.70 & 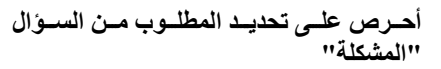 & 9 \\
\hline$Y$ & مرتفع & .700 & 3.52 & قأطلب من الطروع في طلبها. قراعة المشكلة واستيعابها & YY \\
\hline$\mu$ & مرتفع & .685 & 3.51 & فهم أعمق للمشكلة طلاسئلة بصورة تساهم في & $\pi$ \\
\hline
\end{tabular}


فاعلية استراتيجية التصور البصرى فى تنمية مهارات الإملاء والاتجاه نحو الكتابة د. صفوت توفيق هنداوى

\begin{tabular}{|c|c|c|c|c|c|}
\hline$\varepsilon$ & مرتفع & .643 & 3.48 & 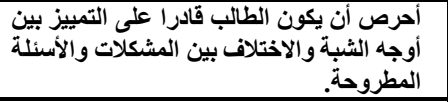 & 11 \\
\hline 0 & مرتفع & .717 & 3.46 & أطشكلة من الطراد حلبها. & $r \varepsilon$ \\
\hline 7 & مرتفع & .724 & 3.42 & 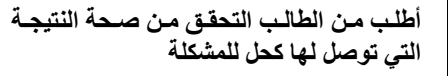 & rᄉ \\
\hline V & مرتفع & .693 & 3.40 & الصحيخ المتكررة أن يكون الطالب قـادراً على تمييز & IV \\
\hline$\Lambda$ & مرتفع & .731 & 3.39 & 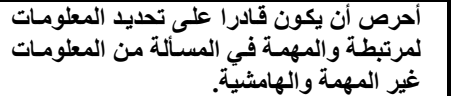 & Ir \\
\hline 9 & مرتفع & .665 & 3.39 & 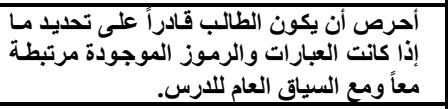 & 10 \\
\hline 1. & مرتفع & .688 & 3.39 & 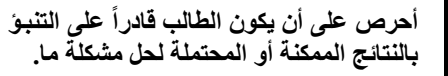 & ri \\
\hline 11 & مرتفع & .684 & 3.37 & 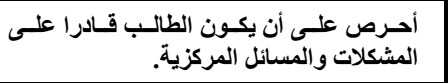 & 1. \\
\hline$r$ & مرتفع & .766 & 3.37 & 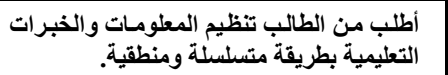 & rV \\
\hline $1 \mu$ & مرتفع & .747 & 3.33 & 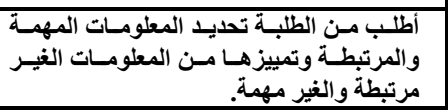 & ro \\
\hline $1 \varepsilon$ & مرتفع & .745 & 3.30 & أحختلفة أنَ يميز مثكلة مالب الاتجاهات و التصورات & 19 \\
\hline 10 & مرتفع & .743 & 3.30 & 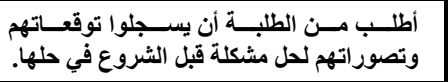 & ru \\
\hline 17 & مرتفع & .761 & 3.29 & 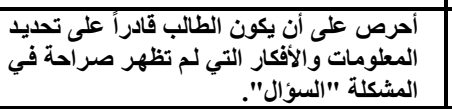 & 17 \\
\hline 18 & مرتفع & .708 & 3.24 & | نوعية الملاحظتات والاستتناجات. معيار للحكم على & $1 \varepsilon$ \\
\hline 11 & مرتفع & .740 & 3.23 & 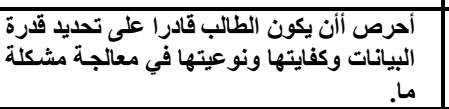 & r. \\
\hline 19 & مرتفع & .776 & 3.21 & مصدرقية ألنصادرن. الطالب قـادراً على تحديـد & 11 \\
\hline$r$ & مرتفع & .880 & 3.04 & سههي " رسم كروكي" قبل الثروع فئ مخها. & Tr \\
\hline
\end{tabular}

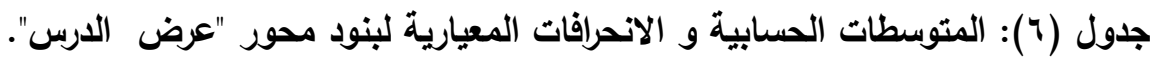
تبين نتائج الجدول (T) أن مستويات تقييم المعلمات لاستخدام التفكير الناقد في عرض الدرس جاءت جميعها في المستوى المرتفع. وقد جاء في الترتيب الأول العبارة رقم(9) "أحرص على تحديب المطلوب من السؤال "المشكلة" ، و 
في التزتيب الأخير العبارة رقم بr. "أطلب من الطالب تمثيل الشككلة في

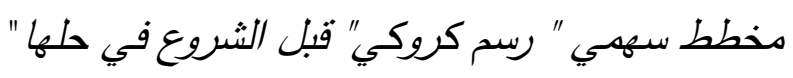

السال (Y): ما مدى تقييم المعلمات لمعوقات استخدام أنماط التفكير الناقد

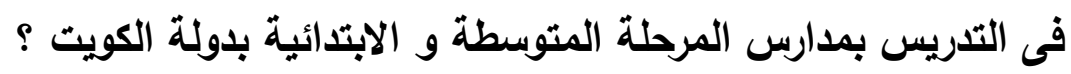

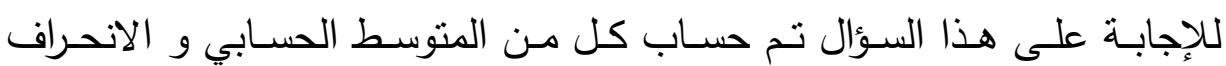
المعياري ، لفقرات محور المعوقات ، و نم اعتماد المستويات التالية للتقييم:

\begin{tabular}{|c|c|c|c|c|c|}
\hline 雮: & 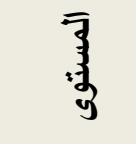 & $\begin{array}{ll}\overline{9} & \overline{3} \\
\overline{9} & \overline{3} \\
\overline{3}\end{array}$ & 事 $\frac{3}{3}$ & لفقرات & \\
\hline 1 & مرتة & 700 & 3.48 & جاء. & $\varepsilon$ \\
\hline r & مرتة & 780 & 3.28 & شتركيزة تنفيّر الطالب على كيفية الحصول على & سז \\
\hline r & مرتفع & .704 & 3.28 & التركيز في & ro \\
\hline$\varepsilon$ & مرتفع & .699 & 3.25 & | لالدرشفة & rq \\
\hline 0 & مرتفع & .751 & 3.21 & ألمعتومات الطالب على الآخرين في الحصول على & $r v$ \\
\hline 7 & مرتفع & .848 & 3.13 & ضعف الادافع & $\Gamma \varepsilon$ \\
\hline V & مرتفع & .749 & 3.13 & 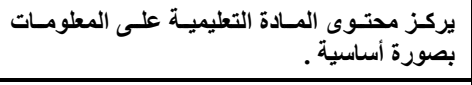 & $\varepsilon r$ \\
\hline$\Lambda$ & مرتفع & .792 & 3.08 & جوانبها. في حل المشكلة دون معرفة مختسف & T4 \\
\hline 9 & مرتفع & .884 & 3.01 & مراجع أخرى. المدسي هو المرجع الوحيد ولا تتوفر & $\varepsilon$. \\
\hline 1. & متوه & 932 & 2.96 & 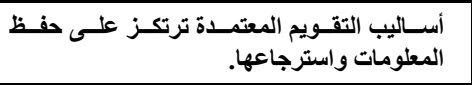 & $\leqslant 0$ \\
\hline 11 & 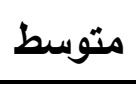 & 352 & 2.86 & ألفهيراف الثناقيواد التطليمية لا تركز على مهارات & $\varepsilon \varepsilon$ \\
\hline r & مـ & 54 & 2.84 & 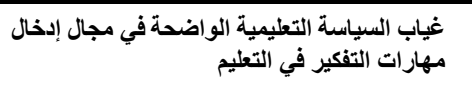 & r. \\
\hline rו & مسو & 52 & 2.80 & 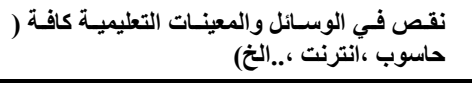 & r \\
\hline $1 \varepsilon$ & متوبط & 64 & 2.67 & الثراي الآذرة التعبير عن الرأي في المجتمع واحترام & 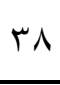 \\
\hline 10 & متوبط & .891 & 2.67 & 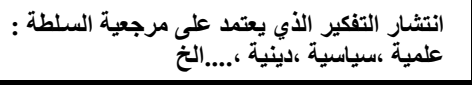 & rq \\
\hline
\end{tabular}


فاعلية استراتيجية التصور البصرى فى تنمية مهارات الإملاء والاتجاه نحو الكتابة د. صفوت توفيق هنداوى

\begin{tabular}{|c|c|c|c|c|c|}
\hline 17 & متوسط & .859 & 2.65 & أتمكنية من تمحقيق التفكير الناقاق تهلدر وقت الحصة ولا & $\varepsilon r$ \\
\hline iv & متوبط & .910 & 2.64 & 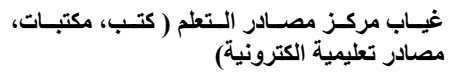 & Tr \\
\hline & متوسط & .440 & 3.00 & \multicolumn{2}{|c|}{ المحور الكلى } \\
\hline
\end{tabular}

جدول (V): المتوسطات الحسابية و الانحرافات المعيارية على محور معوقات التفكير الناقد؟

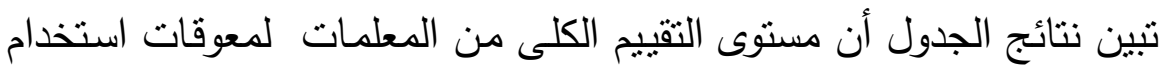

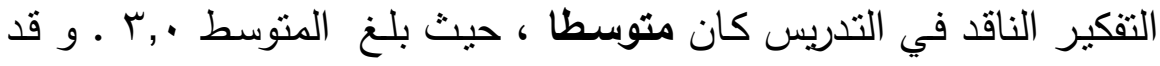

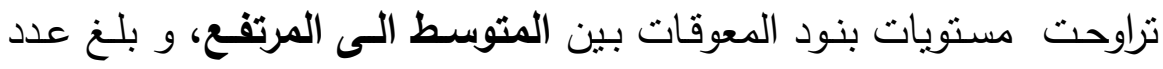
العبارات التي حصلت على مستوى مرتفع 9 عبارات، و عدد العبارات التي لـوني حصلت على مستوى متوسط ^ عبارات، واهم المعوقات التي تواجه المعلم كما تشير قيمتها حسب قيم المتوسط الحسابي لها ، هي عدم وجود خطة

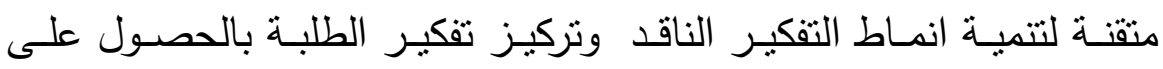

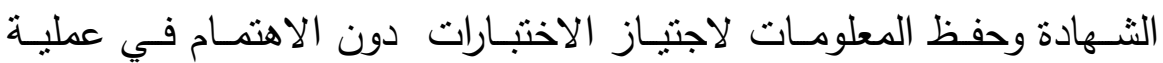
• التعلم

السؤال (ץ): هل توجد فروق ذات دلالة احصائية فى تقييم المعلمات لاستخدام التفكير الناقد فى التدريس و معوقاته تبعا للاختلاف المرحلة التعليمية؟ اسـتخدم اختبـار ت للفـروق بـين المجموعـات لحسـاب الفـروق بـين اسـتجابات المعلمات في المرحلة الابتدائية و في المرحلة المتوسطة لمدى استخدام التفكير الناقد في التدريس و معوقاته، ويعرض في الجدول (^)

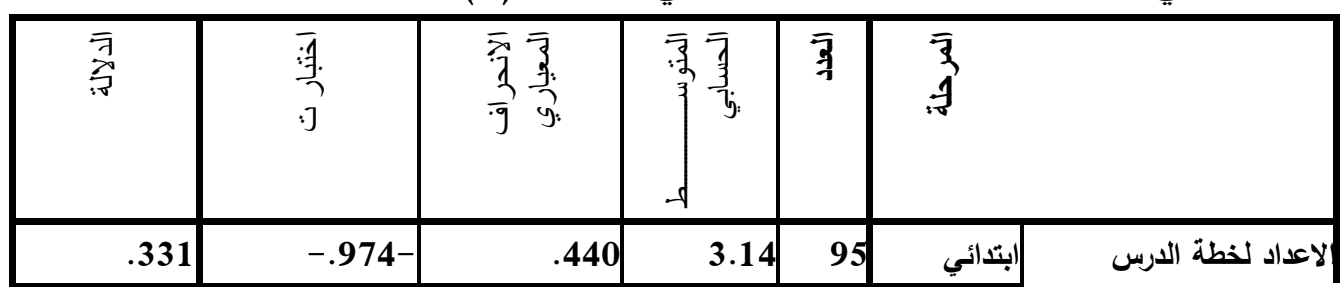

Doi: $10.12816 / 0041725$ 


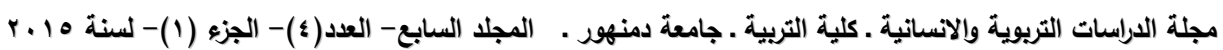

\begin{tabular}{|c|c|c|c|c|c|c|}
\hline & & .538 & 3.20 & 298 & متوسط & \\
\hline \multirow[t]{2}{*}{.183} & $-1.335-$ & .397 & 3.31 & 95 & |ابتدائي & \multirow{2}{*}{ عرض الدرس } \\
\hline & & .462 & 3.38 & 298 & متوسط & \\
\hline \multirow[t]{2}{*}{.482} & $-.703-$ & .438 & 2.97 & 95 & |ابتدائي & \multirow{2}{*}{ لمعوقات } \\
\hline & & .442 & 3.01 & 298 & متوسط & \\
\hline
\end{tabular}

جدول (^): اختبار ت للفروق على محاور الاستبيان تبعا للمرحلة الدراسية تتير نتائج الجدول (^) الى عدم وجود فروق ذات دلالـة احصائية بين تقييم المعلمات فى المرحلة الابتدائية وفى المرحلة المتوسطة لكل من استخدام انماط التفكير الناقد فى كل من الاعداد للادر، وعرض الدرس، و معوقات الاستخدام ،

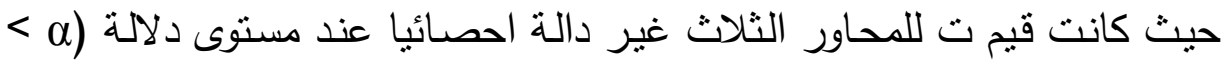
$(\cdot, \cdot 0$ وتدل تلك النتائج على تقارب استخدام المعلمات في كل من المرحلة المتوسطة و

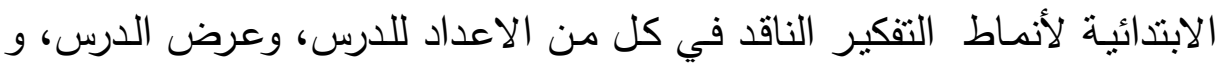
معوقات الاستخدام السؤال ( ) : : هل توجد فروق ذات دلالة احصائية فى تقييم المعلمات لاستخدام التفكير الناقد فى التريس و معوقاته تبعا للاختلاف مادة التخصص؟

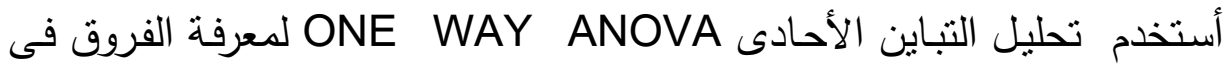
تقييم محاور الاستبيان بين معلمات العلوم و الرياضيات ، كما هو موضح في

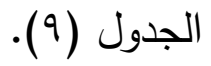

\begin{tabular}{|c|c|c|c|c|c|c|}
\hline 䮩 & $\cdot \mathrm{g}$ & 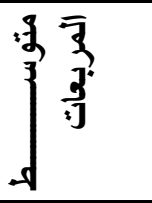 & $\frac{3}{3}$ & 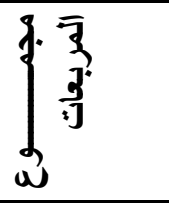 & & بدر التباين \\
\hline .519 & .756 & .202 & $r$ & .605 & بين المجموعات & \multirow{3}{*}{ الاعداد لخطة الارس } \\
\hline & & .267 & 389 & 103.718 & داخل المجموعات & \\
\hline & & & 392 & 104.323 & المجموع & \\
\hline \multirow[t]{3}{*}{.619} & .594 & .120 & $r$ & .359 & بين المجموعات & \multirow{3}{*}{ عرض الدرس } \\
\hline & & .201 & 389 & 78.309 & داخل المجموعات & \\
\hline & & & 392 & 78.667 & المجموع & \\
\hline
\end{tabular}

rrq 
فاعلية استراتيجية التصور البصرى فى تنمية مهارات الإملاء والاتجاه نحو الكتابة د. صفوت توفيق هنداوى

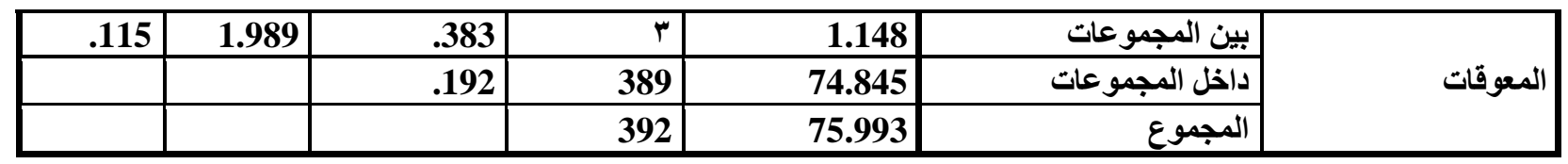

جدول (9): تحليل التباين للفروق على محاور الاستبيان تبعا للمادة الدراسية

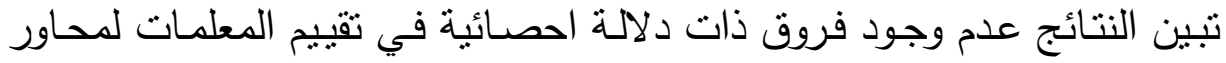
اسـتخدام التفكيـر الناقـد في الاعـداد للـدرس ، و عـرض الــرس ، و معوقـات

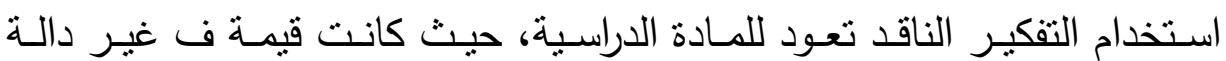

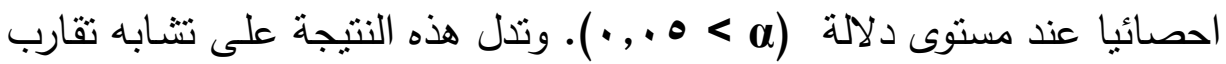

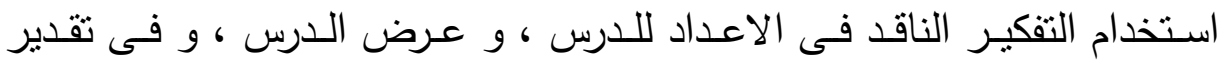
معوقات استخدام التفكير بين المعلمات بمواد الرياضيات و العلوم. السؤال (0) : هل توجد فروق ذات دلالة احصائية في تقييم المعلمات لاستخدام التفكير الناقد فى التدريس و معوقاته تبعا لسنوات الخبرة في التدريس؟ أستخدم تحليل التباين الأحادي ONE WAY ANOVA لمعرفة الفروق في في

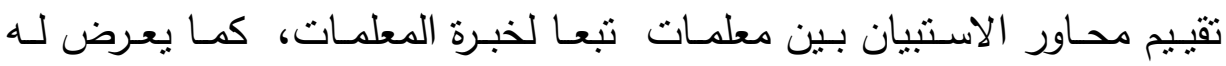

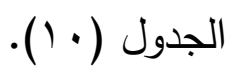

جدول (• (): تحليل التباين للفروق على محاور الاستبيان تبعا لسنوات الخبرة

\begin{tabular}{|c|c|c|c|c|c|c|}
\hline 商 & $\cdot g$ & 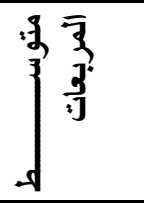 & 交 & $\left\{\begin{array}{l}x=\overline{3} \\
\bar{a} \\
\overline{3}\end{array}\right.$ & & التبا: \\
\hline \multirow[t]{3}{*}{.017} & 3.440 & .899 & 3 & 2.696 & بين المجموعات & \multirow{3}{*}{ 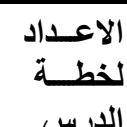 } \\
\hline & & .261 & 389 & 101.626 & داخل المجموعات & \\
\hline & & & 392 & 104.323 & |المجموع & \\
\hline \multirow[t]{3}{*}{.015} & 3.528 & .694 & 3 & 2.083 & بين المجموعات & \multirow{3}{*}{ الدرس } \\
\hline & & .197 & 389 & 76.584 & داخل المجمو عات & \\
\hline & & & 392 & $\begin{array}{l}8.667 \\
\end{array}$ & المجموع & \\
\hline \multirow[t]{3}{*}{.011} & 3.736 & .709 & 3 & 2.128 & بين المجموعات & \multirow{3}{*}{ المعوقات } \\
\hline & & .190 & 389 & 73.864 & داخل المجموعات & \\
\hline & & & 392 & 75.993 & المجموع & \\
\hline
\end{tabular}

جدول (• (1): تحليل التباين للفروق على محاور الاستبيان تبعا لسنوات الخبرة 
تبـين النتـائج وجـود فـروق ذات دلالـة احصـائية في تقيميم المعلمـات لمحساور

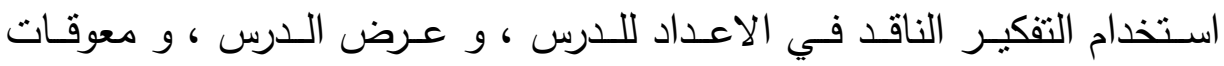
استخدام التفكير الناقد تعود لخبرة المعلمات، حيث كانت قيمة ف دالة احصائيا عند مستوى دلالة (

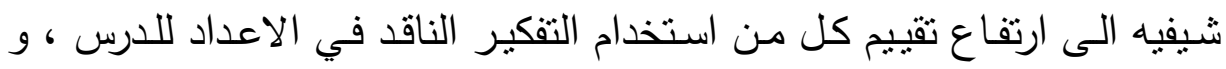

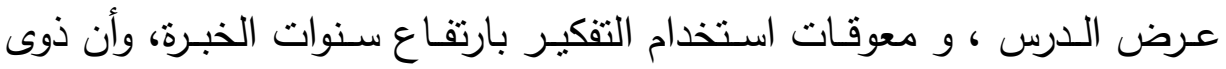

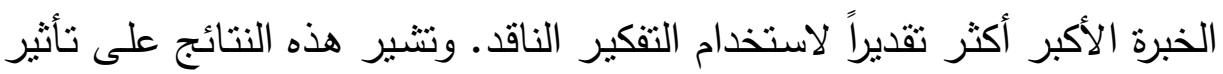
خبرة المعلمـات على استخدام التفكير الناقد في التدريس بالمرحلة المتوسطة و هوهير

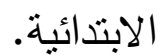

السؤال (7) : هل توجد فروق ذات دلالة احصائية في تقييم المعلمات لاستخدام

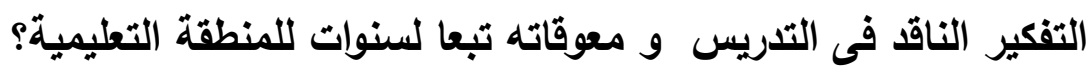
تم استخدام تحليل التباين الأحادي ONE WAY ANOVA لمعرفة الفروق في مبي

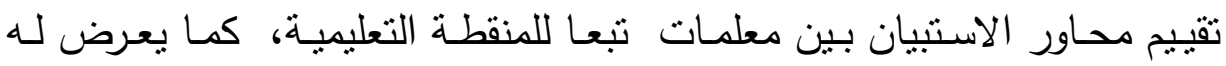

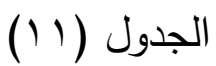

\begin{tabular}{|c|c|c|c|c|c|c|}
\hline 牙 & $\mathrm{g}$ & 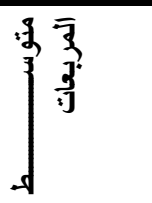 & 等 & 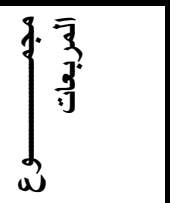 & & لدر التباين \\
\hline .519 & .756 & .202 & 3 & .605 & بين المجموعات & \multirow{3}{*}{ الارعداد لخطة } \\
\hline & & .267 & 389 & 103.718 & داخل المجموعات & \\
\hline & & & 392 & 104.323 & المجموع & \\
\hline .619 & .594 & .120 & 3 & .359 & بين المجموعات & \multirow{3}{*}{ عرض الدرس } \\
\hline & & .201 & 389 & 78.309 & داخل المجموعات & \\
\hline & & & 392 & 78.667 & المجموع & \\
\hline .115 & 1.989 & .383 & 3 & 1.148 & بين المجموعات & \multirow{3}{*}{ المعوقات } \\
\hline & & .192 & 389 & 74.845 & داخل المجموعات & \\
\hline & & & 392 & 75.993 & المجموع & \\
\hline
\end{tabular}

جدول (1 (1): تحليل التباين للفروق على محاور الاستبيان تبعا للمنطقة التعليمية 
تبين النتائج عدم وجود فروق ذات دلالة احصائية في تقيم المعلمات لمحاور

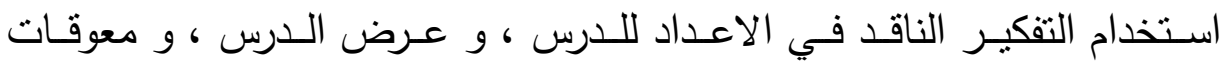

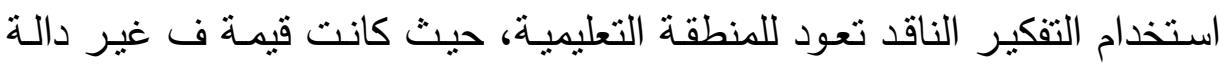

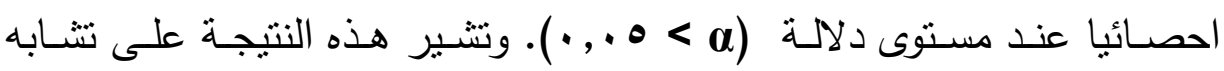
تقارب استخدام التفكير الناقد في الاعداد للارس ، و عرض الدرس ، و في تقدير

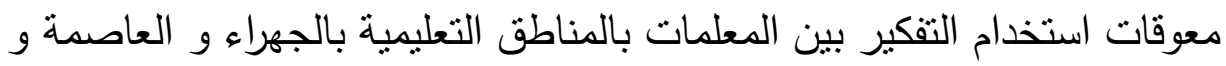
الأحمدي و الفروانية.

ملخص النتائجج:

•ثير النتائج الى أن المعلمات يستخدمن تتمية التفكير الناقد في التدريس للطلبة

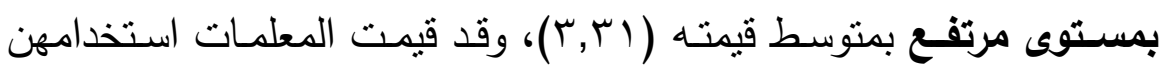

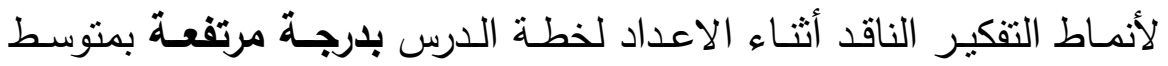

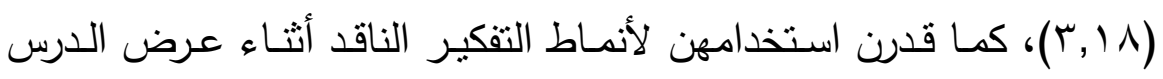

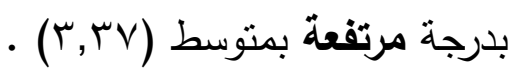

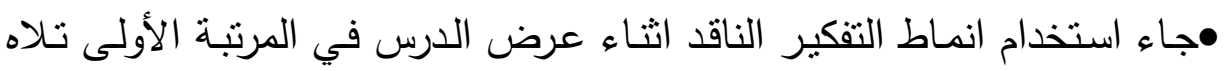
استخدامه اثثاء الاعداد للخطة. •مستويات تقييم المعلمات لاستخدام التفكير الناقد في الاعداد لخطة الدرس قد الاعد

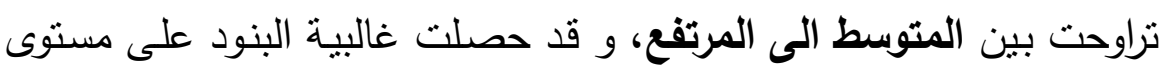
مرتفع (V) عبارات، وحصلت ع عبارة واحدة على مستوى منخفض. وقد جاء

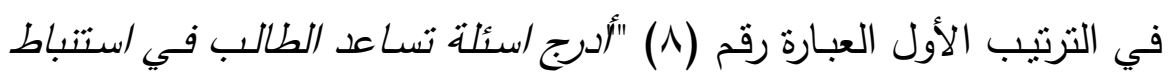
الأحداث وحلول للمشكلات " بمستوى مرتفع، و في الترتيب الأخير العبارة رقم

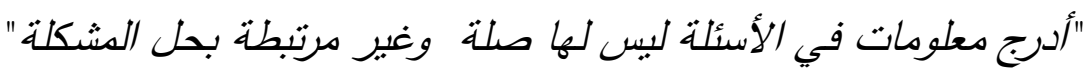
بمستوى متوسط. •مستويات تقيم المعلمـات لاستخدام التقكير الناقد في عرض الدرس جاءت

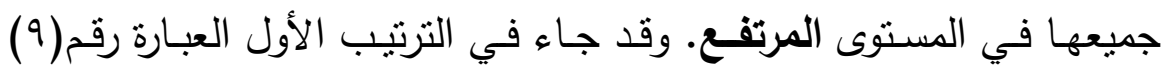


أحرص على تحديد المطلوب من السؤال "المشكلة، و في التزتيب الأخير

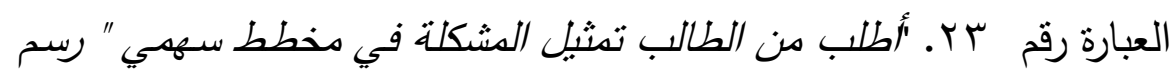
كروكي" قبل الثروع في حلها ".

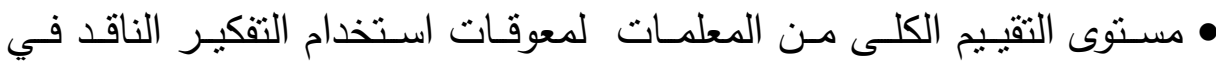
التدريس كان متوسطا ، حيث بلـغ المتوسط (•,r)، وبلـغ عدد العبارات

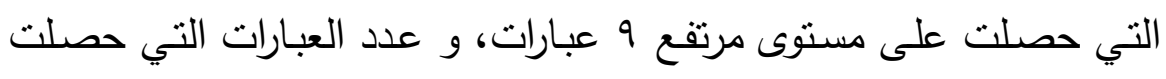
على مستوى متوسط 1 عبارات. •أهم المعوقات التي تواجه المعلم كما تشير قيمتها حسب قيم المتوسط الحسابي

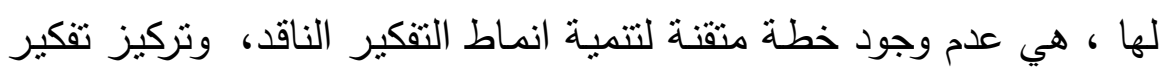

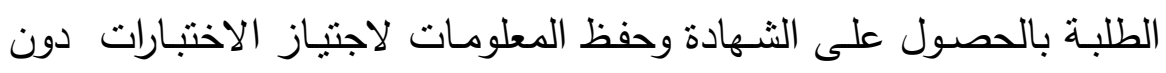
الاهنمام في عملية التعلم .

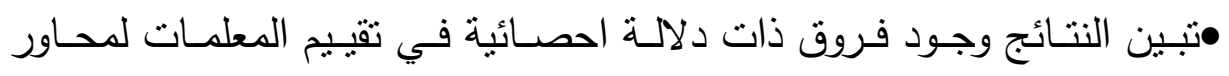
استخدام التفكير الناقد في الاعداد للدرس ، و و عرض الدرس ، و و معوقات استخدام التفكير الناقد تعود لخبرة المعلمات، حيث تشير الفروق في قيم المتوسطات باختبار شيفيه الى ارتفاع تقييم كل من استخدام التفكير الناقد

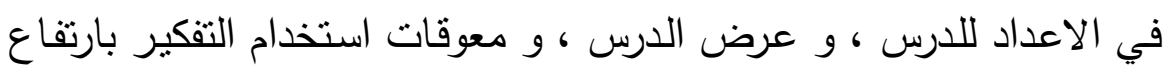

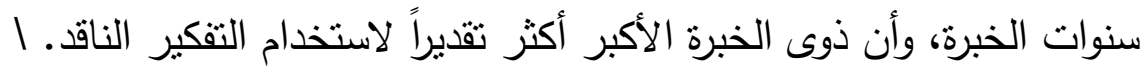

\section{الخاتمة والتوصيات :}

في إطار حدود الدراسة وإجراءاتها وما توصلت إليه من نتائج نتير لأهمية تتمية

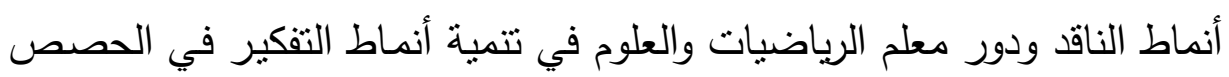

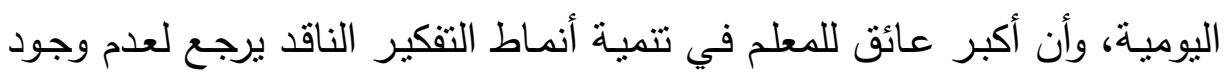
خطة متقنة لتتمية انماط التفكير الناقد، لذا توصي الدراسة بأن تقوم وزارة التربية 
فاعلية استراتيجية التصور البصرى فى تنمية مهارات الإملاء والاتجاه نحو الكتابة د. صفوت توفيق هنداوى

1.إعادة تتظيم مقررات الرياضيات والعلوم بحيث تتضمن أنشطة وتمـارين

لتنمية النماط التفكير الناقد.

r.إعادة تنظيم "كتاب المعلم" في مادتي الرياضيات والعلوم، حيث ينم ادراج

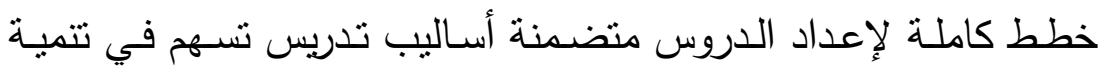

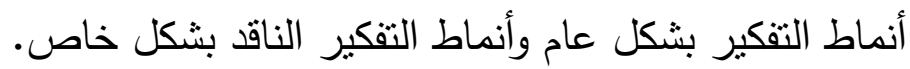

r.إعـداد دورات تدريبيـة لمعلمـات الرياضـيات والعلـوم لتـدريبهم على آليـة

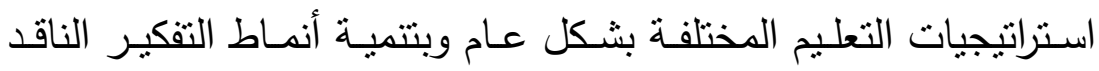

بشكل خاص. 


\section{قائمة المراجع}

\section{أولاً: المراجع العربية:}

•ابراهيم، فاضل خليل (1 . . ب) مستوى التفكير الناقد لدى طلبة التاريخ في كليتي الأداب والتربيـة بجامعـة الموصـل، مجلـة اتحـاد الجامعـات العربيـة، الأمانـة العامـة لاتحـاد

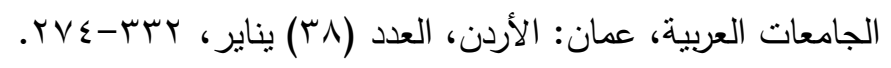

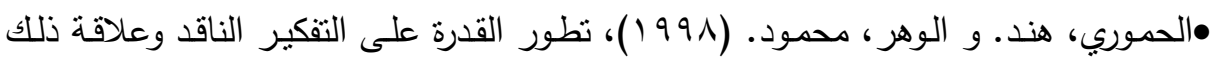
بالمستوى العمـري والجنس وفرع الدراسـة، دراسـات (العلـوم التربويـة) عمـادة البحث

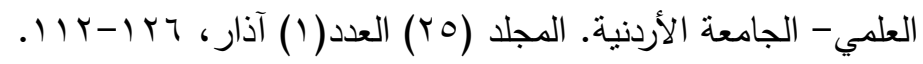

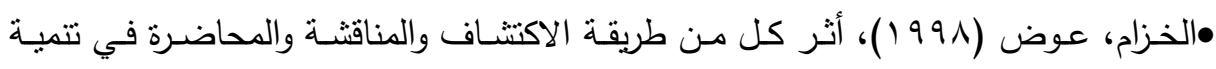

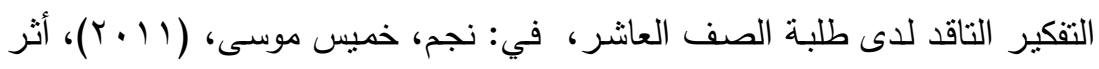
استخدام أسلوب حل المشكلات في تدريس الرياضيات في تتمية التفكير التاقد لدى

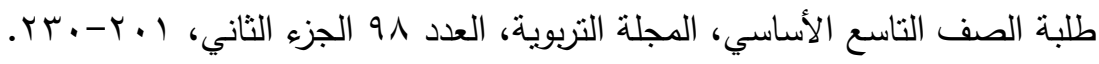
•الزعبي، طلال عبداله (0 . . r). أثنر استخدام طريقـة التدريس فوق المعرفي في تحصيل الطلبة لبعض المفاهيم العليمة، وفي تتمية بعض مهارات التفكير الناقد لديهم، مجلة

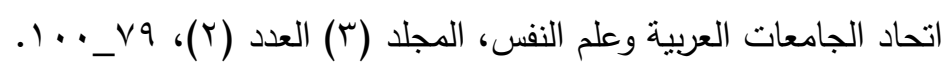

•المهوس، وليد بن ابراهيم (r · . r). الحاسوب وتتمية التفكير الناقد، مجلة البحث في التربية

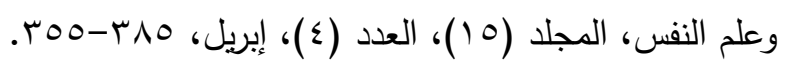

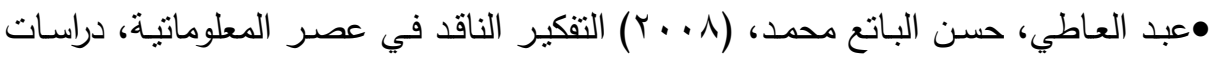

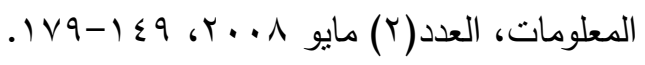

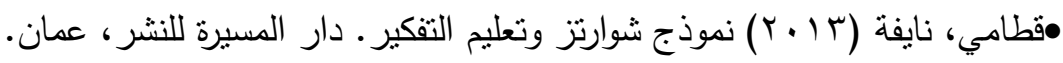

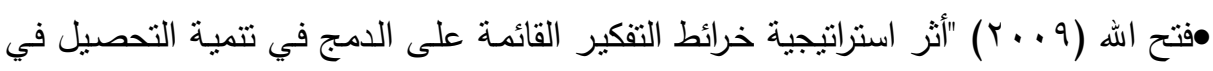

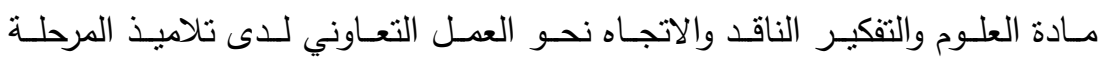

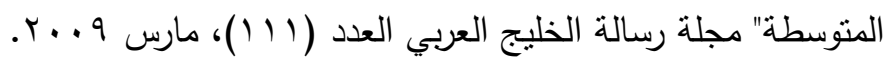
•كرم، إبراهيم (Y99 (1)). دور المدرس في تتمية التفكير الناقد لدى طلاب المواد الاجتماعية

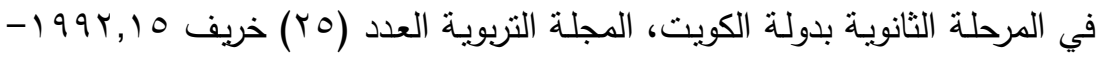


فاعلية استراتيجية التصور البصرى فى تنمية مهارات الإملاء والاتجاه نحو الكتابة د. صفوت توفيق هنداوى

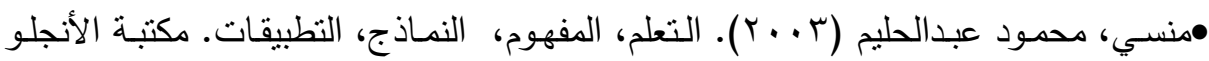

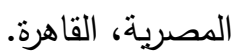

•نجم، خميس موسى، (1) ب (1)، أثر استخدام أسلوب حل المشكلات في تدريس الرياضيات

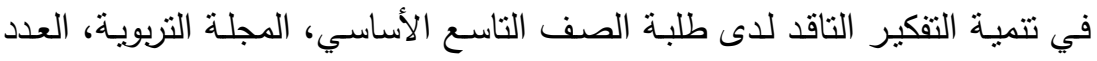

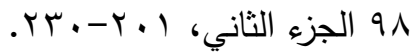

\section{ثنانياُ: المراجع الأجنية:}

-Cai, J. \& Moyer, J. (1995). Middle School Students' Understanding of Average: A Problem-solving Approach. Eric, ED (389574).

-Elliott, B. (2000), The Influence of an Interdisciplinary Course on Critical Thinking Skills, DAI-A, 60(9), 3287.

-Koleza, E. \& Iatridou, M. (2006). The Role of Problem Solving in Raising Self-esteem and Changing Conceptions of PreService Teachers about Mathematics, International Journal of Learning, 13 (1), 69-78.

-Krulik, S., \& Rudnick, J. (1980) Problem Solving: A handbook for teachers, Boston, MA: Allyn and Bacon.

-Moore, W., McCann, H., \& McCann, J. (1985), Creative and Critical Thinking ( $2^{\text {nd }}$ ed), Boston, MA: Houghton Miffling Company.

-Wilkins, C. (2008) Critical Thinking: Why Is It So Hard to Teach?, Arts Education Policy Review, 109 (4), 21-32. 


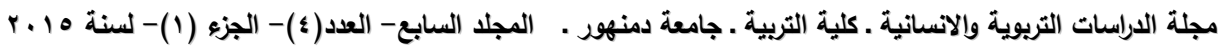

